\title{
Leaf water potential of field crops estimated using NDVI in ground-based remote sensing - opportunities to increase prediction precision
}

\author{
Xuejun Dong ${ }^{\text {Corresp., } 1}{ }^{,}$Bin Peng ${ }^{2}$, Shane Sieckenius ${ }^{1}$, Rahul Raman ${ }^{1,3}$, Matthew M. Conley ${ }^{4}$, Daniel I. Leskovar ${ }^{1}$ \\ ${ }^{1}$ Texas A\&M AgriLife Research and Extension Center at Uvalde, Uvalde, TX, United States \\ 2 Yancheng Institute of Technology, Yancheng City, Jiangsu, China \\ 3 Department of Soil and Crop Sciences, Texas A\&M University, College Station, TX, United States \\ 4 USDA-ARS, U.S. Arid-Land Agricultural Research Center, Maricopa, AZ, United States \\ Corresponding Author: Xuejun Dong \\ Email address: xuejun.dong@ag.tamu.edu
}

Remote-sensing using normalized difference vegetation index (NDVI) has the potential of rapidly detecting the effect of water stress on field crops. However, this detection has typically been accomplished only after the stress effect led to significant changes in crop green biomass, leaf area index, angle and position, and few studies have attempted to estimate the uncertainties of the regression models. These have limited the informed interpretation of NDVI data in agricultural applications. We built a ground-based sensing cart and used it to calibrate the relationships between NDVI and leaf water potential (LWP) for wheat, corn, and cotton growing under field conditions. Both the methods of ordinary least-squares (OLS) and weighted least-squares (WLS) were employed in data analysis, and measurement errors in both LWP and NDVI were considered. We also used statistical resampling to test the effect of measurement errors of LWP on the uncertainties of model coefficients. Our data showed that obtaining a high value of the coefficient of determination did not guarantee a high prediction precision in the obtained regression models. Large prediction uncertainties were estimated for all three crops, and the regressions obtained were not always significant. The best models were obtained for cotton with a prediction uncertainty of $27 \%$. We found that considering measurement errors for both LWP and NDVI led to reduced uncertainties in model coefficients. Also, reducing the sample size of LWP measurement led to significantly increased uncertainties in the coefficients of the linear models describing the LWP-NDVI relationship. Finally, potential strategies for reducing the uncertainty relative to the range of NDVI measurement are discussed. 


\title{
Leaf water potential of field crops
}

estimated using NDVI in ground-based

remote sensing - opportunities to increase

prediction precision

${ }_{5}$ Xuejun Dong ${ }^{1}$, Bin Peng ${ }^{2}$, Shane Sieckenius ${ }^{1}$, Rahul Raman ${ }^{1,3}$, Matthew M. Conley ${ }^{4}$, and Daniel I. Leskovar ${ }^{1}$

\author{
${ }^{1}$ Texas A\&M AgriLife Research and Extension Center at Uvalde, Uvalde, TX, USA \\ ${ }^{2}$ Yancheng Institute of Technology, Yancheng City, Jiangsu, China \\ ${ }^{3}$ Department of Soil and Crop Sciences, Texas A\&M University, College Station, TX, \\ USA \\ ${ }^{4}$ USDA-ARS, U.S. Arid-Land Agricultural Research Center, Maricopa, AZ, USA
}

Corresponding author:

Xuejun Dong ${ }^{1}$

Email address: xuejun.dong@ag.tamu.edu

\begin{abstract}
Remote-sensing using normalized difference vegetation index (NDVI) has the potential of rapidly detecting the effect of water stress on field crops. However, this detection has typically been accomplished only after the stress effect led to significant changes in crop green biomass, leaf area index, angle and position, and few studies have attempted to estimate the uncertainties of the regression models. These have limited the informed interpretation of NDVI data in agricultural applications. We built a ground-based sensing cart and used it to calibrate the relationships between NDVI and leaf water potential (LWP) for wheat, corn, and cotton growing under field conditions. Both the methods of ordinary least-squares (OLS) and weighted least-squares (WLS) were employed in data analysis, and measurement errors in both LWP and NDVI were considered. We also used statistical resampling to test the effect of measurement errors of LWP on the uncertainties of model coefficients. Our data showed that obtaining a high value of the coefficient of determination did not guarantee a high prediction precision in the obtained regression models. Large prediction uncertainties were estimated for all three crops, and the regressions obtained were not always significant. The best models were obtained for cotton with a prediction uncertainty of $27 \%$. We found that considering measurement errors for both LWP and NDVI led to reduced uncertainties in model coefficients. Also, reducing the sample size of LWP measurement led to significantly increased uncertainties in the coefficients of the linear models describing the LWP-NDVI relationship. Finally, potential strategies for reducing the uncertainty relative to the range of NDVI measurement are discussed.
\end{abstract}

\section{INTRODUCTION}

The accurate determination of leaf water potential (LWP) of field crops plays an important role in agricultural irrigation scheduling (Kramer, 1988; Jones, 2004), regional crop health surveys (Pu et al., 2004; Maciel et al., 2020), and in the screening of drought tolerance of crop genotypes for use in arid and semi-arid regions (Kumar and Singh, 1998). Yet traditional methods using the leaf pressure chamber or hygrometer are destructive, time-consuming, and not efficient enough for quantifying a large number of crop genotypes (Mart et al., 2016). This challenge may be overcome by the application of modern remote-sensing techniques (Jones and Vaughan, 2010; Gago et al., 2015; Ihuoma and Madramootoo, 2017). The normalized difference vegetation index (NDVI) derived from low-cost sensors measuring reflectance spectrum in the visible (VIS) and near infrared (NIR) bands, has been traditionally used mainly as a course 'greenness' index, to indicate canopy cover and plant vigor (Rouse et al., 1974; Carlson and Ripley, 1997). Recently, NDVI has been used to infer the effect of water availability and 
water stress in plants (Irmak et al., 2011; Aguilar et al., 2012; Hunink et al., 2015; Bronson et al., 2017; Hunsaker et al., 2007). NDVI was also used to characterize changes in shoot water content of sesame during drydown (Dong et al., 2021). For most instances, however, what NDVI actually captures is most likely the accumulated effect of changed leaf water status on plant growth, as indirectly indicated by structures involving water such as leaf area index, or green biomass, instead of the leaf water potential directly. Waiting until the stress effect has led to significant changes in crop biomass and generic NDVI detection may be too late to guide timely crop management, such as irrigation scheduling. Excluding this confounding effect regarding changes in plant biomass, as well as the confounding effects due to environmental conditions, Elsayed et al. (2011) successfully demonstrated the direct linkage between LWP and spectral reflectance obtained from the VIS and NIR bands for wheat and maize. They used climate chambers to only allow light intensities to change in the short-term of 2-3 hrs while keeping other factors, such as humidity and temperature, unchanged. This allowed them to observe the rapid reduction in LWP during the early stage of leaf water loss when the change in leaf water content may or may not show up, as seen from the concept of the pressure-volume relations during leaf water loss (Cheung et al., 1975). The biophysical mechanisms underlying the changes in vegetation indices in relation to water stress lie in the changes in leaf reflectance from the VIS and NIR bands. The reduced NDVI due to water stress may be caused by the increased red band reflectance associated with decreased chlorophyll content or absorption (Carter, 1993), or alternatively, it may originate from the reduced NIR reflectance associated with reduced cell wall-air interfaces (Grant, 1987) or changes in morphology, such as reduced leaf thickness with the reduction of LWP (Syvertsen and Levy, 1982; Knapp and Carter, 1998; Slaton et al., 2001).

The strong and direct linkage between the observed changes in LWP and the concomitant changes in selected spectral indices (Elsayed et al., 2011) calls for further applications to survey leaf water status for a large number of crop genotypes, as well as under field conditions where the rapid change in light condition is the main factor influencing leaf water potentials. Several other researchers investigated the feasibility of remotely detecting leaf/canopy water status using the airborne or ground-based sensing tools accompanied with LWP measurement (Stimson et al., 2005; Mastrorilli et al., 2010; Baluja et al., 2012; Zarco-Tejada et al., 2012; Maciel et al., 2020). By precisely measuring needle spectral properties using a portable spectrometer, Stimson et al. (2005) determined that NDVI captured the water potential signals of needles of Pinus edulis $\left(R^{2}=0.35\right)$, but not those of Juniperus monosperma. The reason of the difference was presumably due to the reduced reflectance and albedo caused by the denticulate leafy shoots of $J$. monosperma as opposed to the straight needles of $P$. edulis that allowed them to be tightly packed and measured by the spectrometer. Baluja et al. (2012) found that both the selected spectral indices such as NDVI and thermal indices were highly effective in detecting the variability of LWP of a rain-fed vineyard due to natural variability of soil properties. Yet, the correlation between LWP of a citrus orchard and NDVI was weaker $\left(R^{2}=0.24\right)$ than that with crown temperature or chlorophyll fluorescence calculated from a micro-hyperspectral imagery (Zarco-Tejada et al., 2012). Field measurements spanning multiple years in a coffee plantation (Maciel et al., 2020) documented the usefulness of NDVI in remote estimation of LWP of coffee plants both in the dry season and rainy season $\left(R^{2}=0.82\right)$. However, Mastrorilli et al. (2010) cautioned about the operative use of NDVI in irrigation scheduling for tomato, due to the narrow range of the NDVI signals as well as "errors innate to the measuring technique".

Despite the comprehensive nature of the above cited works (Zarco-Tejada et al., 2012), the fieldmeasured data points of LWP were almost always sparse, as compared with those from the remote sensing platforms, and very few of the above-mentioned studies provided estimates of errors or uncertainties of the regression coefficients or those of the predictions by the obtained regression models (but see Rallo et al., 2014). Because both NDVI and LWP are measured values, they both carry statistical uncertainties. Ignoring them in the data analysis may lead to missed opportunities to identify the dominant factors influencing the prediction precision of the models, thus affecting the informed interpretation of NDVI data in agricultural and biological application. In the case of remote sensing of LWP in particular, a narrow response range of NDVI might suggest large relative errors; thus, the practical implication of having a higher or a lower value of coefficient of determination can better be assessed by considering error propagation from the independent to the dependent variables. A fuller account of measurement errors can be found in the description of physical systems (Taylor, 1982; Bevington and Robinson, 2003), and readily usable routines have been developed (Reed, 1989, 1992; Press et al., 1992; Cantrell, 2008; Reed, 2010, 2015) but less utilized to analyze biological data. 
As mentioned above, a major limiting factor for calibrating the LWP-NDVI relationship for field crops is in acquiring sufficient number of measurements of LWP using one of the accepted reference techniques. For example, using the pressure chamber, about 3-6 leaf samples per treatment are typically employed to measure LWP (Mastrorilli et al., 2010; Baluja et al., 2012). When there are more samples to measure within a limited time frame, the sample size of LWP may be reduced. But it is unknown how an increased error due to reduced sample size of LWP would affect the uncertainties of the model coefficients of the LWP-NDVI relationship? Answers to this question are critical for improving the efficiency by which the LWP-NDVI relationship is calibrated, but have rarely been addressed in the literature.

Ground-based sensing platforms have been developed to assist in field crop phenotyping (White and Conley, 2013; Bai et al., 2016; Barker et al., 2016; Zhang et al., 2019). Murray et al. (2016) developed an automated, high-clearance phenotyping vehicle to accommodate tall crops such as corn. In this study, the utility of the sensing cart design of White and Conley (2013) was improved upon, and extended by adding a backpack sensing frame that can be carried by one person to survey tall crops. To minimize the confounding effects of changed biomass or green leaf area, LWP and NDVI were measured concurrently at different times of a day for different crops under field conditions. The objectives of this study were to:

1. apply and test a push-wheel sensing cart for phenotyping field crops of wheat, corn and cotton;

2. develop the regression equations describing LWP as a function of NDVI for different crops by considering measurement errors in both LWP and NDVI; and

3. test the effect of measurement errors of LWP on the prediction precision of the obtained models.

\section{MATERIALS AND METHODS}

\section{Application and construction of a ground-based phenotyping tool}

To assist in field crop phenotyping efficiently and in a consistent manner, we developed a portable proximal sensing cart based on the model of White and Conley (2013). We added wheel assembly improvements to the cart frame, facilitating easy maneuverability by one person in field conditions, as well as adding nested threaded clamps to adjust the cart width, allowing crop measurement with different row spaces (Fig. 1). Attached to the cart are three highly accurate canopy temperature sensors, one ultrasonic crop displacement sensor, one active light NDVI sensor, and a marine grade GPS receiver (A-F in Fig. 2). We also constructed a backpack frame that allows selected measurement of NDVI in tall crops, such as corn, sorghum and sesame (G in Fig. 2). The ACS-430 Crop Circle sensor measures canopy reflectance from three optical channels (red - $670 \mathrm{~nm}$, red-edge - $730 \mathrm{~nm}$, and NIR - $780 \mathrm{~nm}$ ), and NDVI was calculated as (Gong et al., 2003)

$$
\mathrm{NDVI}=\frac{\rho_{780}-\rho_{670}}{\rho_{780}+\rho_{670}}
$$

where $\rho_{780}$ and $\rho_{670}$ represent reflectance at NIR and red band, respectively. To allow us standardized accurate customizable environmental data sampling, we utilized a Campbell Scientific CR3000 voltage data recorder including a CF memory card and with its CRBasic language data collection program execution functions. We subsequently acquired precise raw sensor potentials and their associated GPS coordinate strings, recorded to table structured digital records of $200 \mathrm{~ms}$ granularity (companies and products are not endorsed by the authors and are presented for educational purposes only). A full list of the CRBasic program driving the CR3000 datalogger is available as Supplementary Computer Code S1.

\section{Field data acquisition and collection}

Field crops of wheat, corn, and cotton were grown under deficit- and full irrigation regimes in a center pivot field at the Texas A\&M AgirLife Research and Extension Center at Uvalde, TX in the 2017-2018 growing season. The full irrigation was determined based on full-replenishment of the crop evapo-transpiration (ET) measured at the Research Center facility, while deficit irrigation was determined as $60 \%$ of the full irrigation. Diurnal changes in canopy NDVI and leaf water potentials for the three crops were measured on five clear days (see Table 1 for further information). Canopy NDVI for wheat and cotton was measured using the sensing cart, while that of corn was measured using the backpack sensing frame. Leaf water potential was measured using a PMS-615 Pressure Chamber (PMS Instrument Company, Albany, OR USA), with the high pressure generated by pure nitrogen gas. For wheat, one transect encompassing a full 


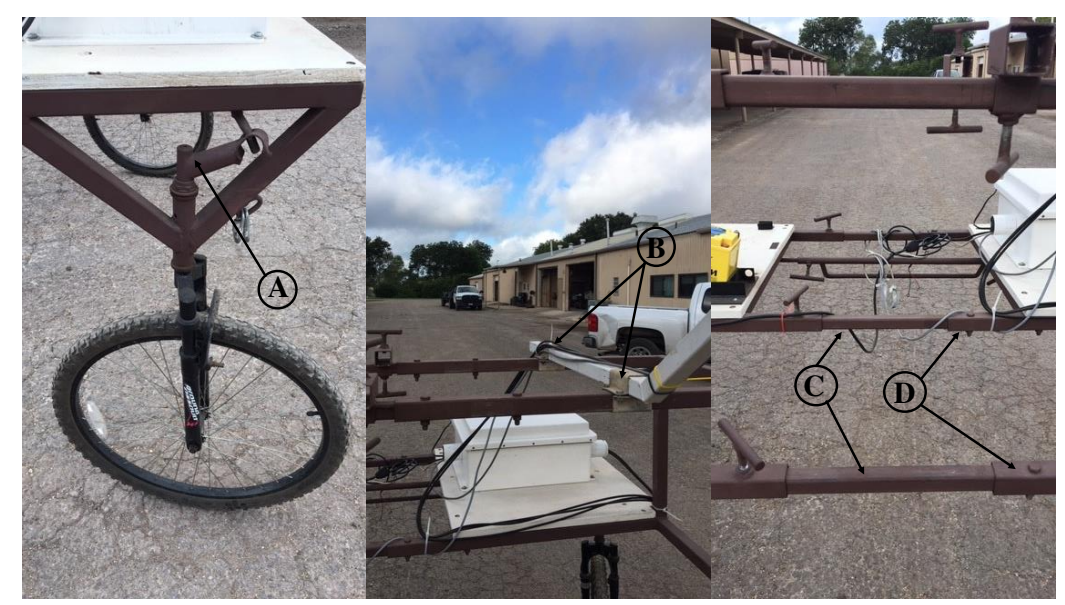

Figure 1. Highlights of the design features of the push-wheel sensing cart. (A) The rear wheels are installed with a steering mechanism to facilitate cart movement along a slightly curved row line as seen in a center-pivot field. (B) The sensor-mounting arm is fixed to the cart frame by two adjustable brackets, allowing flexible placement of the sensor-mounting arm along the width of the cart. (C) The smaller-sized tubings fitted into larger-size ones (D) to allow the width of the cart (i.e., the distance between the left and right side wheels) to be adjustable from $152 \mathrm{~cm}$ to $203 \mathrm{~cm}$, a feature useful for measuring crops with different row spacings. Photo credit: Shane Sieckenius.
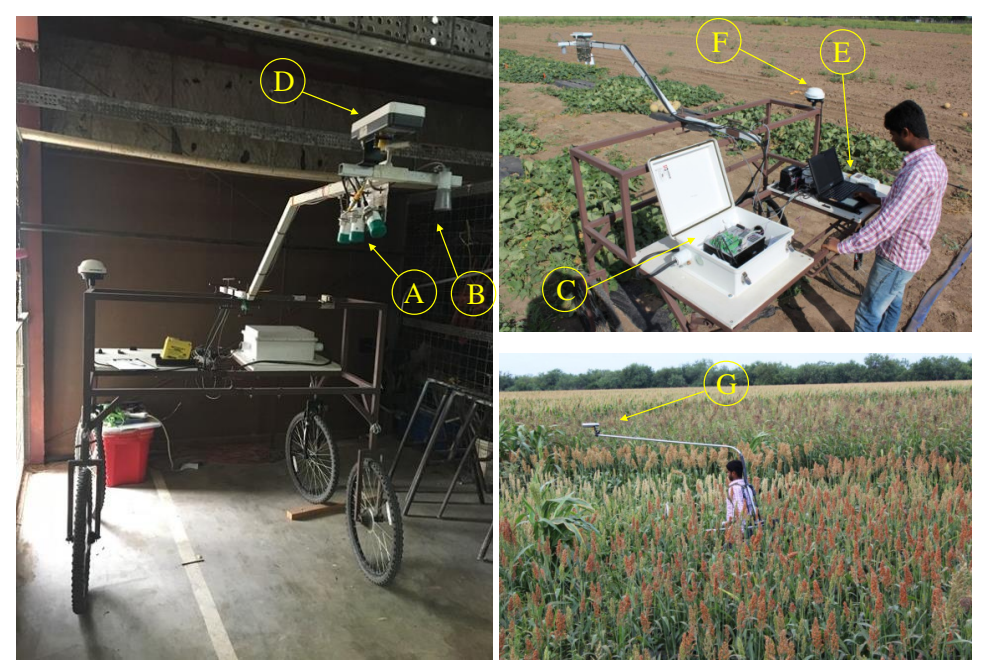

Figure 2. Configuration of sensors on the push-wheel sensing cart). (A) Three Apogee radiometers to pointing at different angles to measure canopy temperature. (B) An ultra-sonic sensor to measure canopy height. (C) CR3000 data logger housed in an enclosure to record data from radiometers and the ultra-sonic height sensor. (D) ASC-430 Crop Circle sensor to measure canopy vegetation indices. (E) GeoSCOUT Datalogger to record Crop Circle sensor data. (F) Hemisphere 101 GPS receiver with the signal-splitting cable connecting to the CR3000 and GeoSCOUT dataloggers. (G) A detached ACS-Crop Circle sensor mounted atop a backpack sensing frame (along with the GeoSCOUT Datalogger) for measuring tall vegetation. Photo credit: Xuejun Dong. 
and a deficit irrigation field was used, while for corn and cotton, a circular transect within a quarter of the center pivot field was used for the measurement. Within the circular transect, six equal divisions were delineated-each at least 30-m long, covering $15^{\circ}$ angle in the circle and randomly assigned to receive either deficit or full irrigation treatment, with the six sections designated as six plots, i.e., deficit-1, full-1, full-2, deficit-2, deficit-3 and full-3, starting at the west side and ending at the east side of the circular path. On each of the five days selected for making field measurement, NDVI was scanned within the transect repeatedly once every hour from early morning to late afternoon. On each day, the datalogger was turned on before start of the first scan, and kept on until completing the day's measurement in late afternoon. Each hour when NDVI was measured, 4-6 healthy and representative leaves of corn, cotton or wheat were chosen for measuring leaf water potentials (LWP) under field conditions (Fig. 3). For wheat, the flag leaves were selected to make the LWP measurement; for corn and cotton, the fourth leaf counting down from the fully expanded youngest leaf were used for the LWP measurement. To minimize water loss from the leaves enclosed in the chamber during pressurization, one moistened, $15-\mathrm{cm}$ diameter filter paper was lined against the interior of the chamber wall and maintained moistened throughout the measurements.

To document changes in green biomass during the growing season, leaf area index (LAI) for each of the crops was measured using a LI-3100 Area Meter (Li-Cor Inc., Lincoln, NE USA) through destructive sampling. The measurement was made weekly or once every two weeks during the periods when there were significant changes in green biomass. For wheat, three random shoot samples were collected by harvesting a $20-\mathrm{cm}$ long of a representative row from both deficit and full irrigation segments of the transect. For corn and cotton, one representative plant per plot was harvested to measure total leaf area on each measurement period. LAI was estimated based on total green leaf area per plant, row spacing and population density (shown in Table 1).

\section{Data processing and statistical analysis}

In this study, the data analysis is focused on the measured NDVI and its relationship with LWP. Over five days, about 1.3 million lines of data were recorded using the ground-based phenotyping tools on three crops. Some of the data lines were recorded while the sensor was in rest awaiting next round of scans. This was done in order to avoid the datalogger being turned off and back on repeatedly during the day, causing inadvertent errors. These unwanted readings during idle period, as well as other unwanted readings, were deleted during data processing according to recorded GPS coordinates, as well as the Coordinated Universal Time (UTC), in order to match the sensor data with field plots/treatments and time of measurement on different days. This initial data processing was done in Minitab (Version 17.3.1, 2016, Minitab Inc.). The datalogger recorded UTC time was translated into the Central Standard Time (CST) during the local day-light-savings time period by the relation CST $=\mathrm{UTC}-5$. The summarized data of NDVI and LWP were then further analyzed as described below.

Two methods were employed to conduct the least-squares regression analysis describing the relationship between measured values of NDVI $(x)$ and leaf water potential $(y)$ in the form

$$
Y=m X+c,
$$

where $Y$ and $X$ represent adjusted/calculated values corresponding to measured $y$ and $x, m$ and $c$ represent the slope and $y$-intercept of the model.

1. The first method is default to most statistical software packages where a common uncertainty in $y$ is assumed, and the measurement errors in $x$ are considered negligible as compared to those of $y$. Specifically, the regression analysis was conducted using GraphPad Prism 6 (GraphPad Software, Inc., 2015). Statistical differences among and between the slopes and the y-intercepts of the linear regressions representing different treatments were compared using ANCOVA in Prism 6. The uncertainties in the coefficients $m$ and $c$ were calculated according to Taylor (1982) and implemented using a Minitab macro 'lsq.mac' (see Supplementary Computer Code S2 and Dataset S1). The maximum relative errors in predicted LWP given a specific NDVI observation was estimated according to rules of error propagation (Taylor, 1982):

$$
\frac{\delta y}{|\bar{y}|} \leq \frac{1}{|\bar{y}|}\left[\left|\frac{\partial y}{\partial m}\right| \delta m+\left|\frac{\partial y}{\partial c}\right| \delta c\right]=\frac{1}{|\bar{y}|}(|\bar{x}| \delta m+\delta c),
$$


where $\delta y, \delta m$, and $\delta c$ are estimated uncertainties in $y, m$, and $c$, and $\bar{x}$ and $\bar{y}$ are the mean values of $x$ and $y$, respectively. The first method is subsequently referred to as the method of OLS (Ordinary Least Squares).

2. The second method is based on the principle of weighted linear least-squares considering measurement uncertainties in both coordinates (York, 1966). In this method, the scheme of Deming (1943) was used to give different data points different weighting factors $\omega\left(x_{i}\right)$ and $\omega\left(y_{i}\right)$ that were defined as the inverse squares of the uncertainties $\delta\left(x_{i}\right)$ and $\delta\left(y_{i}\right)$ (i.e., $\omega\left(x_{i}\right)=1 / \delta^{2}\left(x_{i}\right)$ and $\left.\omega\left(y_{i}\right)=1 / \delta^{2}\left(y_{i}\right)\right)$, and the best values of $m$ and $c$ of Eq. 2 were identified by minimizing the sum of the weighted squared residuals $S$ as:

$$
S=\sum_{i=1}^{N}\left[\omega\left(x_{i}\right)\left(x_{i}-X_{i}\right)^{2}+\omega\left(y_{i}\right)\left(y_{i}-Y_{i}\right)^{2}\right],
$$

where $x_{i}$ and $y_{i}$ are observed values and $X_{i}$ and $Y_{i}$ and calculated ones with $i$ running from 1 to $N$. York (1966), McIntyre et al. (1966) and Williamson (1968) developed the full solution of the dual-uncertainties least-squares problem, which has received wide recognition in geosciences and physical sciences (Cantrell, 2008). However, the same method appears to be less-utilized by biologists who may equally be faced with the same type of statistics problems as do geoscientists, physicists and chemists. For this reason, it is necessary to summarize the main steps for finding the model parameters and their uncertainties in this second method, based on equations of York (1969) and Reed (1992).

With the "overall weight" for the $i$ th data point defined as

$$
Z_{i}=\frac{\omega\left(x_{i}\right) \omega\left(y_{i}\right)}{m^{2} \omega\left(y_{i}\right)+\omega\left(x_{i}\right)},
$$

Eq. 4 can be written as

$$
S=\sum_{i=1}^{N} Z_{i}\left(y_{i}-m x_{i}-c\right)^{2}
$$

The pursuit of minimization of Eq. 6 leads to a "least-squares cubic" in the form of

$$
m^{3} \sum_{i=1}^{N} \frac{Z_{i}^{2} U_{i}^{2}}{\omega\left(x_{i}\right)}-2 m^{2} \sum_{i=1}^{N} \frac{Z_{i}^{2} U_{i} V_{i}}{\omega\left(x_{i}\right)}-m\left[\sum_{i=1}^{N} Z_{i} U_{i}^{2}-\sum_{i=1}^{N} \frac{Z_{i}^{2} V_{i}^{2}}{\omega\left(x_{i}\right)}\right]+\sum_{i=1}^{N} Z_{i} U_{i} V_{i}=0
$$

where $Z_{i}$ is from Eq. 5, $U_{i}=x_{i}-\sum_{i=1}^{N} Z_{i} x_{i}\left(\sum_{i=1}^{N} Z_{i}\right)^{-1}$ and $V_{i}=y_{i}-\sum_{i=1}^{N} Z_{i} y_{i}\left(\sum_{i=1}^{N} Z_{i}\right)^{-1}$. Eq. 7 can be solved for $m$ to obtain the best value of the slope. However, since $Z_{i}, U_{i}$ and $V_{i}$ are themselves all functions of $m$, the equation is actually a pseudo-least-squares cubic, and the best value of $m$ is obtained through successive iterations starting from a crude estimation, such as from an unweighted least-squares fitting. A least-squares cubic similar to Eq. 7 with the associated iterative solution was developed independently by McIntyre et al. (1966) in analyzing the Rb-Sr isochrons from geological samples. Eq. 7 may also be formulated in pseudo-quadratic- (York, 1969; Reed, 1992) or pseudo-linear form (Williamson, 1968; Reed, 2015), but they all need to be solved iteratively, similar to the cubic case. Using multiple data sets, Reed (1989) demonstrated that finding the correct solution to Eq. 7 can sometimes be tricky and confusing, and provided a direct searching method to quickly "pin down" the true value of $m$ starting from a relatively good "seed" value. Once the best value of $m$ is obtained, the like value of $c$ can be found from

$$
c=\sum_{i=1}^{N} Z_{i} y_{i}\left(\sum_{i=1}^{N} Z_{i}\right)^{-1}-m \sum_{i=1}^{N} Z_{i} x_{i}\left(\sum_{i=1}^{N} Z_{i}\right)^{-1} .
$$

Built on the work of York (1966), Reed (1992) provided a corrected expression of the variance of $m$ :

$$
\delta_{m}^{2}=\frac{S}{N-2} \sum_{i=1}^{N}\left[\frac{1}{\omega\left(y_{i}\right)}\left(\frac{\partial m}{\partial y_{i}}\right)^{2}+\frac{1}{\omega\left(x_{i}\right)}\left(\frac{\partial m}{\partial x_{i}}\right)^{2}\right]
$$


where $S$ is from Eq. 6, $\frac{\partial m}{\partial y_{j}}$ and $\frac{\partial m}{\partial x_{i}}$ can be computed from $x_{i}, y_{i}, \omega\left(x_{i}\right), \omega\left(y_{i}\right)$ and the best value of $m$ (see Appendix of Reed (1992) for the rather involved explicit expressions). The expression for $\delta_{c}^{2}$ (variance of $c$ ) is identical to that of $\delta_{m}^{2}$ but with derivative of $c$ in place of $m$ in Eq. 9 .

Several researchers (McIntyre et al., 1966; York, 1969; Lybanon, 1984; Reed, 1989; Press et al., 1992), and a few others as discussed by Cantrell (2008), have developed computer programs (mainly in Fortran) to implement the algorithms of finding both the best parameter values (i.e., $m$ and $c$ ) and their variances for the least-squares fitting problem with errors in both coordinates. Notably, Cantrell (2008) developed an Excel spreadsheet program to implement the Williamson-York method of bivariate linear fit. Reed (2010) translated his Fortran program into an easy-to-use Excel spreadsheet, and later updated it (Reed, 2015) to account for the situation with correlated $x-y$ uncertainties, one that occurs widely in the study of isotope ratios in geosciences (York, 1969; York et al., 2004). However, in this paper, we only consider the situation with non-correlated $x-y$ uncertainties, because the interested quantities (i.e., NDVI and LWP) were derived from measurements using different types of equipment independently, and thus their uncertainties are assumed to be uncorrelated.

Our second method relied on the use of the Excel spreadsheet 'LLS(SIGMAS).xls' of Reed (2010). Specifically, the Excel function 'Goal seek' was used to obtain the best estimation of coefficient $m$ that ensured a function $g(m)$ (such as Eq. 7) taking the value of zero. Then the best value of $m$ was used to determine the best value of $c$ according to Eq. 8. To facilitate the determination of $m$, it was important to first use the unweighted least-squares routine builtin in 'LLS(SIGMAS).xls' to get a seed value of $m$ which was then input to the 'Goal seek' function to find the best value of $m$ (Reed, 2010). Since the values in both coordinates are adjusted in this method, the uncertainties $\delta m$, and $\delta c$ can be calculated either at the observed points or at the calculated/adjusted points (Reed, 2010). In 'LLS(SIGMAS).xls', this is achieved using a switch: to evaluate the derivatives at the observed points, set PASS=0, or to evaluate them at the calculated/adjusted points, set PASS $=1$. We used the second option (i.e., at the adjusted points) but the differences in results using the two options were generally small for well-correlated data. Equipped with the best estimates of $m$ and $c$ and their variances (see Eq. 9), which are part of the outputs of the above spreadsheet program, the maximum relative errors in predicted LWP using the second method were calculated according to Eq. 3. This method is subsequently referred to as the method of WLS (Weighted Least Squares).

We also used statistical resampling to investigate the effect of measurement errors in LWP on the regression model. In particular, we wanted to see how the reduced sample size of LWP would affect the estimated regression coefficients and their uncertainties. The resampling was done using a Minitab macro 'sem_a.mac' (see Supplementary Computer Code S3 and dataset S2), in which multiple sets of resampled 2 or 3 replicates of LWP values were drawn randomly (with replacement) from the original 4-6 measurements made during the field surveys. The resampled values of LWP were then used as inputs, along with the originally measured values of NDVI, to 'lsq.mac' and 'LLS(SIGMAS).xls', in order to obtain the best estimates of the regression coefficients and their uncertainties using the method of OLS and WLS, respectively. Differences in the regression coefficients (and associated uncertainties) between the situation with resampled LWP values and that with the originally measured LWP values were compared using the One-sample $t$-test available in Minitab.

\section{RESULTS}

\section{NDVI in relation to leaf area index and leaf water potential}

Average values of LAI of wheat, corn and cotton were significantly lower under deficit irrigation than under full irrigation ( $p<0.05$, Fig. 4$)$, especially in the mid- to late growth stages when canopy NDVI and leaf water potentials were measured. These trends in LAI paralleled those in measured NDVI, as seen in corn measured on June 7, 2018 (Supplementary Fig. S1). In the case of the latter, it is evident that the differences between the deficit and full irrigation grew larger with the progression of time during a day. However, the NDVI values of wheat measured on April 12, 2018 exhibit a different trend, one in which the values measured from the deficit irrigation was high than that from the full irrigation, showing an opposite trend with the measured LWP (Fig. 5A). This was an unexpected result, but we did notice that during this day's measurement there was significant lodging in the wheat field. This happened especially after the most recent irrigation event, possibly related to the Hessian fly infection. The measured NDVI 

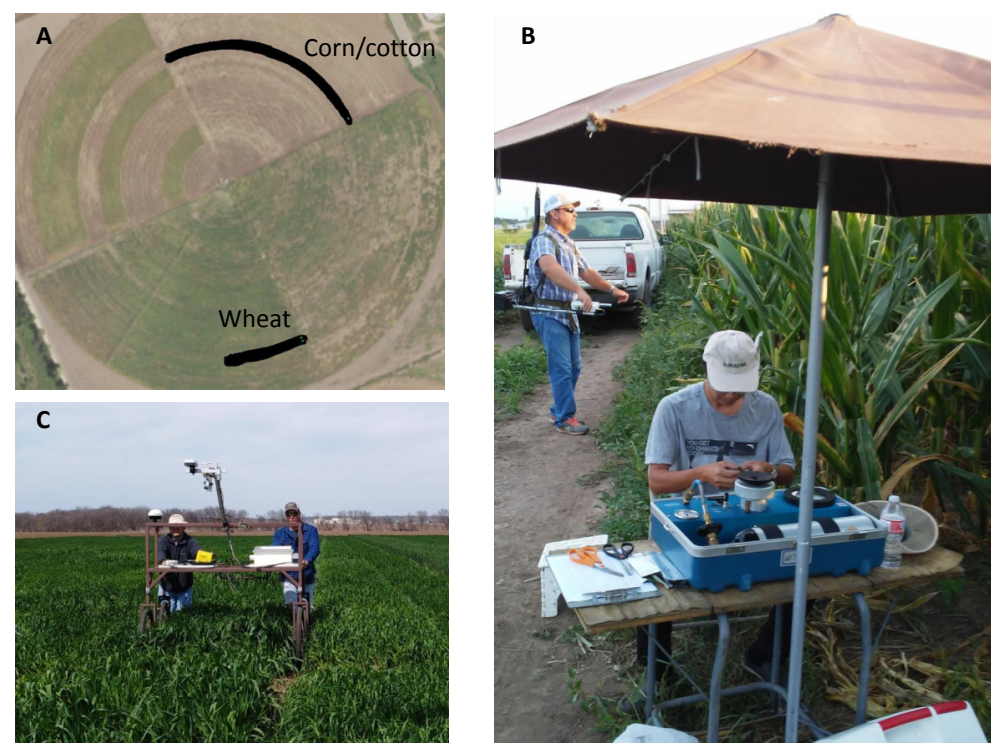

Figure 3. Ground-based phenotyping tools as used in field conditions. (A) Field map showing locations of field plots within a 50-acre center pivot field (Map data $\odot 2018$ Google). Corn and cotton were planted in the northeast quarter, which was subdivided into six pies at $15^{\circ}$ intervals. Wheat was planted in the southwest quarter, with a segment delineated for NDVI scanning, covering a deficit- and full irrigated area. (B) A back-pack sensing frame equipped with an ACS-430 Crop Circle sensor and a GeoScout Datalogger was used to scan the corn plots; also shown is a pressure chamber being used to measure leaf water potential (Photo credit: Xuejun Dong). (C) A push-wheel sensing cart equipped with an ASC-430 Crop Circle sensor, three Apogee radiometers and one ultrasonic height sensor (Photo credit: Gongneng Feng).

Table 1. Summary of crop management of wheat, corn and cotton crops and the field physiological sampling activities in the 2017-2018 growing season.

\begin{tabular}{|c|c|c|c|}
\hline Item & Wheat & Corn & Cotton \\
\hline Variety used & Gallagher & DKC64-69 & DP1044 \\
\hline Day of planting & $11 / 27 / 2017$ & $3 / 7 / 2018$ & $4 / 9 / 2018$ \\
\hline Row spacing $(\mathrm{cm})$ & 19 & 102 & 102 \\
\hline \# Plants $/ \mathrm{m}$ & 150 & 5.7 & 11 \\
\hline Precipitation received $(\mathrm{mm})$ & 126 & 89 & 121 \\
\hline Irrigation applied (mm) & $83 / 62 \dagger$ & $330 / 229$ & $362 / 273$ \\
\hline Day of harvesting & $5 / 14 / 2018$ & $8 / 1 / 2018$ & $8 / 15 / 2018$ \\
\hline Yield (ka/ha) & $4712 \ddagger$ & $7912 / 5746 \S$ & $1225 / 878$ II \\
\hline NDVI/LWP measured & 4/12/2018, 4/19/2018 & $6 / 7 / 2018,6 / 11 / 2018$ & $8 / 9 / 2018$ \\
\hline Min/max air temperature $\left({ }^{\circ} \mathrm{C}\right) \$$ & $15.8 / 30.5,17.4 / 25.1$ & $24.8 / 35.0,24.6 / 35.5$ & $24.9 / 36.5$ \\
\hline Days after planting (DAP) & 136,143 & 92,96 & 113 \\
\hline Growth stage & Grain-filling & Grain-filling & $70 \%$ Boll open \\
\hline \multicolumn{4}{|c|}{$\begin{array}{l}\text { Amount applied in the full and deficit irrigation treatment, respectiv } \\
\text { \$ Grain yield under full irrigation. } \\
\text { § Grain yield under full and deficit irrigation treatment, respectively. } \\
\text { II Lint yield. }\end{array}$} \\
\hline
\end{tabular}


A

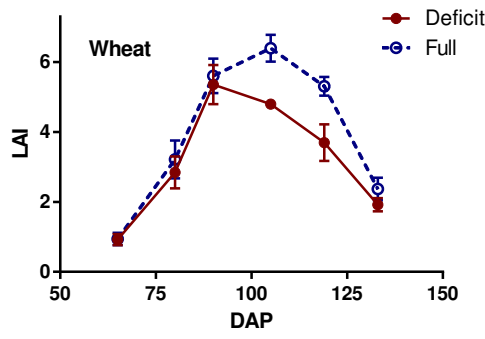

B

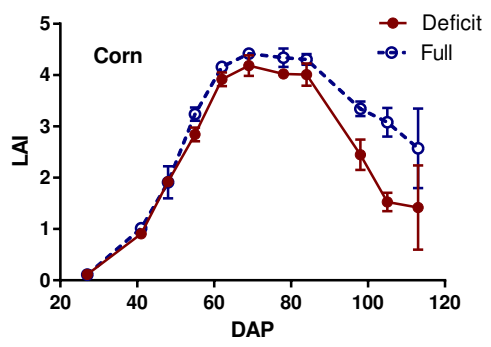

C

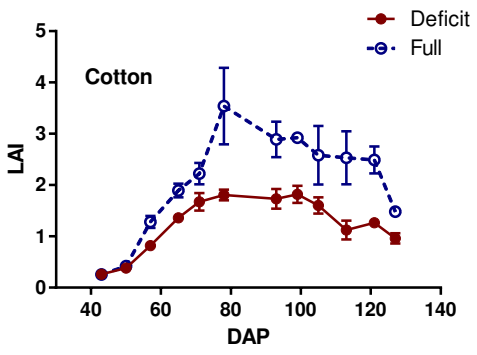

Figure 4. Seasonal trends of leaf area index (LAI) for wheat (A), corn (B) and cotton (C) under full- and deficit irrigation regimes in 2018. LAI was estimated based on harvested sample plants. For wheat, three representative row segments each $20-\mathrm{cm}$ long were harvested in each irrigation treatment once every two weeks from February 1 (65 days after planting, DAP), and for corn and cotton, one plant was harvested in each of the three plots in each irrigation regime once every week starting from April 2 (27 DAP for corn) and May 22 (43 DAP for cotton).

values on April 19, however, show an expected trend, being higher in full than deficit irrigation (Fig. 5B). As a result, except for wheat measured on April 12, a higher LWP was associated with a higher NDVI in the three field crops.

In drawing Fig 5A, the NDVI values measured at 8 am (NDVI $=0.55$ and NDVI $=0.63$ for full and deficit irrigation, respectively; see raw data file NDVI_wheat_apri1_12.xls in the Supplementary material) were not used, since these values were collected when the Crop Circle sensor was not fully warmed up in the relatively cold morning of April 12, 2018, with an air temperature as low as $15.8^{\circ} \mathrm{C}$ at 8 am (see Table 1 and Supplementary Fig. S2). The peculiar observation that the wheat NDVI under deficit irrigation was higher than that under full irrigation as measured on April 12 (Fig. 5) prompted us to inspect the raw data of canopy reflectance measured at the red and NIR bands. As seen in Fig. 6, the higher wheat NDVI on April 12 in the deficit irrigated plots was due both to a lower reflectance at the red band and the higher reflectance at the NIR band, as compared with the plots under full irrigation (see the definition of NDVI in Eq. 1). The observation that the wheat NDVI in plots of deficit irrigation on April 19 was higher than that of the full irrigation plots was, however, due only to the higher red band reflectance associated with the deficit irrigation, because the NIR reflecance was similar between the two irrigation regimes (again see Fig. 6).

Another important point is if there was a significant difference in NDVI within a single day. For winter wheat, this was not tested statistically because the NDVI measurement was not replicated. By visual inspection (Fig. 5A,B), the diurnal trend of NDVI was unclear in both April 12 and 19, which was in contrast to the clear diurnal pattern of LWP in those two days. For corn and cotton, however, there were clear diurnal changes in NDVI (Fig. 5C,D,E). One-way ANOVA ( $n=3$, since each of the NDVI scans for corn or cotton was done with three replicates) indicated that, except for corn under full irrigation on June 11 that exhibited a marginally significant diurnal change $(p=0.056)$, five other diurnal courses of NDVI for corn/cotton all showed significant or highly significant diurnal trends $(p<0.05)$.

Since the relationship between LAI and NDVI was strong (Supplementary Fig. S3), and there was significant differences in LAI values between deficit and full irrigation treatments, we analyzed 
A

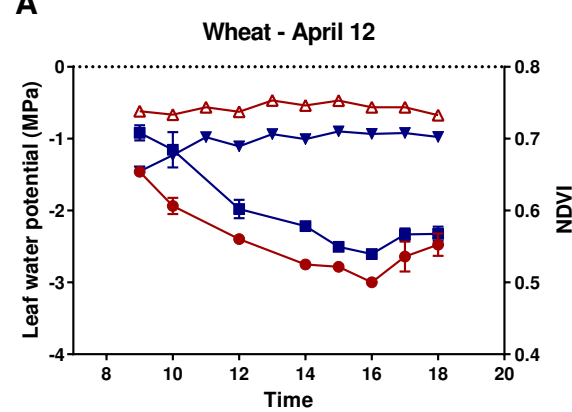

C

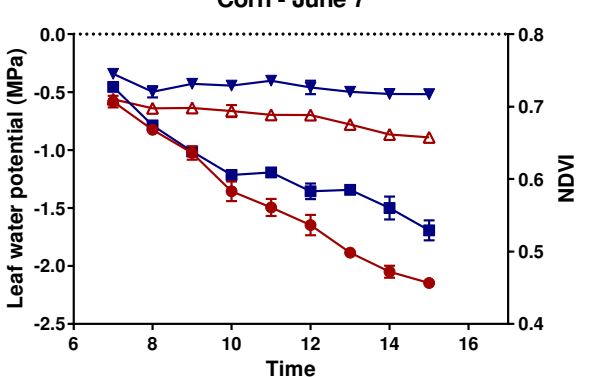

E

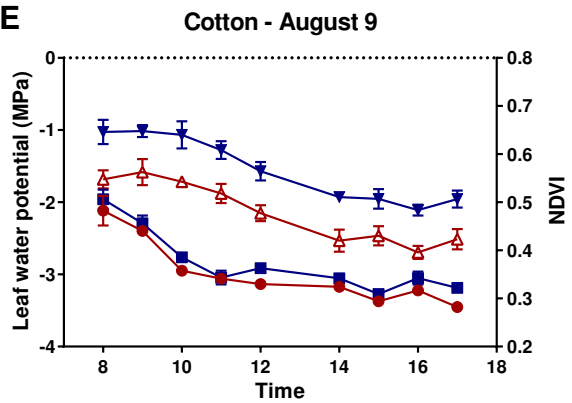

B

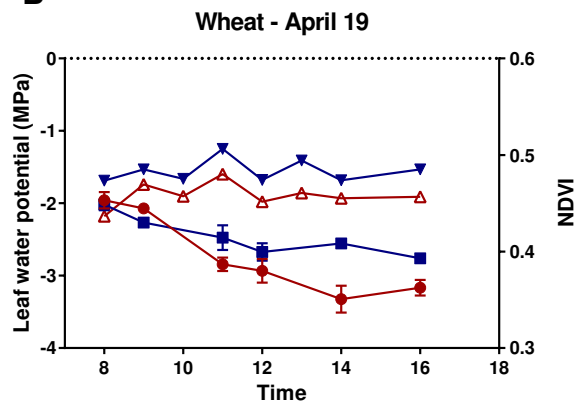

D

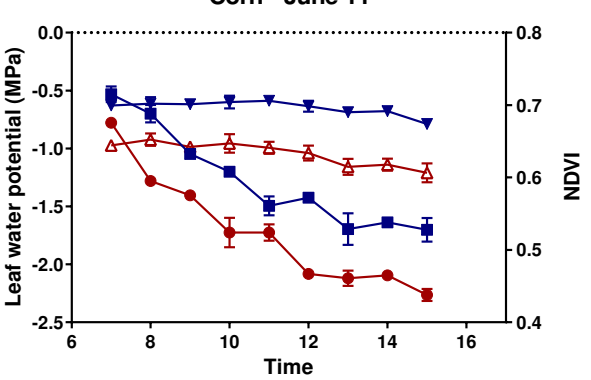

Figure 5. Diurnal variations of leaf water potential (LWP) and canopy NDVI measured for wheat on April 12 and 19, 2018 (A,B), corn on June 7 and 11, 2018 (C, D), and cotton on August 9, 2018 (E) under full and deficit irrigation regimes. Error bars indicate standard errors of means (no error bars shown for NDVI of wheat, since the plots were not replicated).

Table 2. Further information of statistically significant linear regressions describing leaf water potential as a function of NDVI as shown in Fig. 7. Different uppercase letters indicate significant differences in regression slopes or $y$-intercepts for a particular crop type.

\begin{tabular}{|c|c|c|c|c|c|c|}
\hline Crop & Date & Irrigation $\dagger$ & Slope & $y$-Intercept & P-value & $\mathrm{R}^{2}$ \\
\hline Wheat & Apr. 12 & $\bar{F}$ & -31.56 & 19.88 & 0.0001 & 0.93 \\
\hline \multirow[t]{3}{*}{ Corn } & Jun. 7 & $\mathrm{D}$ & $29.55^{A}$ & $-21.71^{B}$ & 0.0001 & 0.89 \\
\hline & Jun. 7 & $\mathrm{~F}$ & $28.85^{A}$ & $-22.15^{C}$ & 0.0272 & 0.53 \\
\hline & Jun. 11 & D & $23.18^{A}$ & $-16.40^{A}$ & 0.0145 & 0.60 \\
\hline \multirow[t]{2}{*}{ Cotton } & Aug. 9 & $\mathrm{D}$ & $5.508^{A}$ & $-5.629^{A}$ & 0.0095 & 0.64 \\
\hline & Aug. 9 & F & $5.051^{A}$ & $-5.708^{A}$ & 0.0117 & 0.62 \\
\hline
\end{tabular}



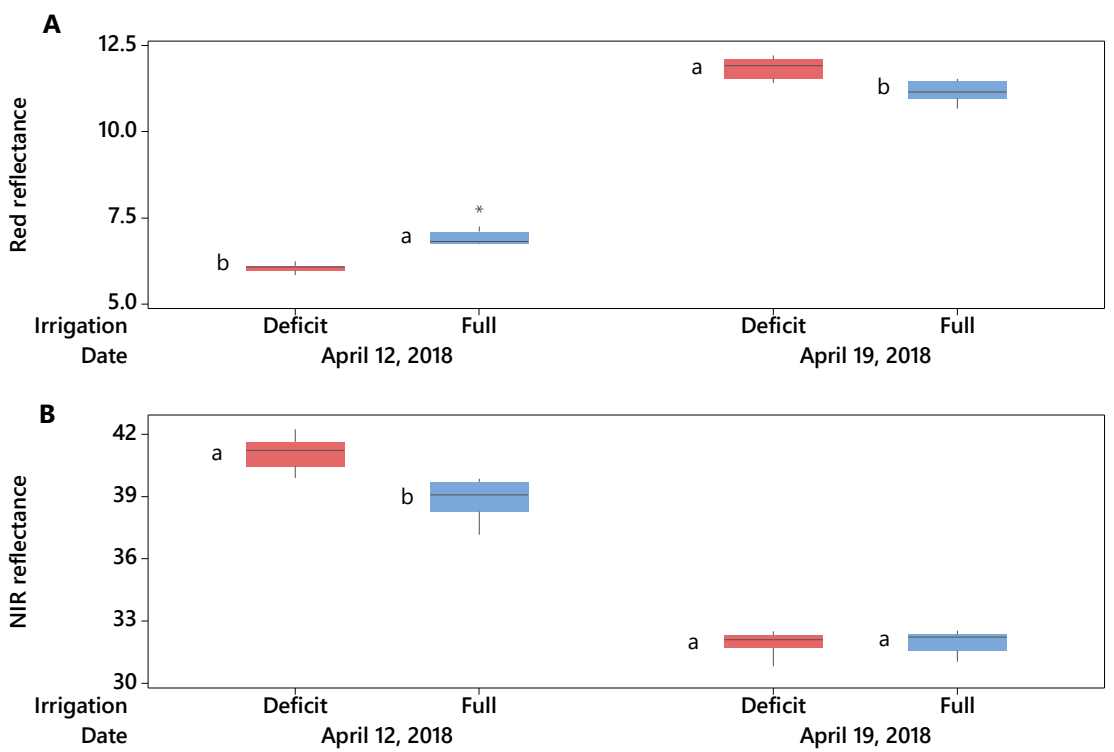

Figure 6. Box plots of mean reflectance values from $670 \mathrm{~nm}$ wavelength (A) and those from $780 \mathrm{~nm}$ wavelength (B) for measurements made in winter wheat plots at 10 times on April $12(n=10)$ and eight times on April $19(n=8)$. Different lower-case letters "a-b" indicate significant difference $(p<0.0005)$ in mean reflectance values at a specific wavelength made on a particular day, while the same lower-case letters " $\mathrm{a}-\mathrm{a}$ " indicate non-significant difference from the $t$-test $(p>0.05)$.

Table 3. Best estimates of the slopes $(m)$ and $y$-intercepts $(c)$, and associated uncertainties ( $\delta m$ and $\delta c)$, for the significant linear regressions (assuming a common uncertainty in all $y$ measurements). The number of data points in each regression is indicated in column $n$, and the relative error for predicted leaf water potential based on uncertainties in $m$ and $c$ is shown in column $\delta Y / Y$.

\begin{tabular}{|c|c|c|c|c|c|c|}
\hline Crop & Date & Irrigation $\dagger$ & $n$ & $m(\delta m)$ & $c(\delta c)$ & $\delta Y / Y$ \\
\hline Wheat & Apr. 12 & $\bar{F}$ & 8 & $-31.56(3.63)$ & $19.88(2.52)$ & 2.52 \\
\hline \multirow[t]{3}{*}{ Corn } & Jun. 7 & $\bar{D}$ & 9 & $29.55(3.90)$ & $-21.71(2.68)$ & 4.53 \\
\hline & Jun. 7 & $\mathrm{~F}$ & 9 & $28.85(10.37)$ & $-22.15(7.54)$ & 12.82 \\
\hline & Jun. 11 & D & 9 & $23.18(7.18)$ & $-16.40(4.55)$ & 5.19 \\
\hline \multirow[t]{3}{*}{ Cotton } & Aug. 9 & $\mathrm{D}$ & 9 & $5.51(1.56)$ & $-5.63(0.75)$ & 0.50 \\
\hline & Aug. 9 & F & 9 & $5.05(1.49)$ & $-5.71(0.85)$ & 0.60 \\
\hline & Aug. 9 & $\mathrm{D} / \mathrm{F}$ & 18 & $4.07(0.93)$ & $-5.04(0.49)$ & 0.34 \\
\hline
\end{tabular}

Table 4. Best estimates of the slopes $(m)$ and $y$-intercepts $(c)$, and associated errors ( $\delta m$ and $\delta c$ ), for the significant linear regressions in Fig. 7 after taking into consideration the measurement errors of both leaf water potential and NDVI. The number of data points in each regression is indicated in the column $n$, and the relative error for predicted leaf water potential based on uncertainties in $m$ and $c$ is shown in the column $\delta Y / Y$.

\begin{tabular}{c|cccccc}
\hline Crop & Date & Irrigation $\dagger$ & $n$ & $m(\boldsymbol{\delta} m)$ & $c(\boldsymbol{\delta} c)$ & $\delta Y / Y$ \\
\hline Wheat & Apr. 12 & $\mathrm{F}$ & 8 & $-28.95(3.02)$ & $18.03(2.13)$ & 2.10 \\
\hline Corn & Jun. 7 & $\mathrm{D}$ & 9 & $31.91(3.40)$ & $-23.31(2.32)$ & 4.04 \\
& Jun. 7 & $\mathrm{F}$ & 9 & $42.17(7.76)$ & $-31.85(5.65)$ & 9.47 \\
& Jun. 11 & $\mathrm{D}$ & 9 & $67.45(22.41)$ & $-44.36(14.35)$ & 16.40 \\
\hline Cotton & Aug. 9 & $\mathrm{D}$ & 9 & $4.75(1.04)$ & $-5.34(0.51)$ & 0.33 \\
& Aug. 9 & $\mathrm{F}$ & 9 & $4.88(1.34)$ & $-5.64(0.73)$ & 0.52 \\
& Aug. 9 & $\mathrm{D} / \mathrm{F}$ & 18 & $4.24(0.77)$ & $-5.19(0.39)$ & 0.27 \\
\hline & \multicolumn{7}{c}{ "D" and "F" represent "deficit" and "full" irrigation. } & &
\end{tabular}


A

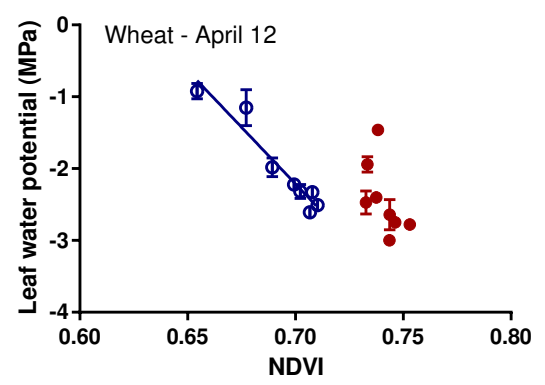

C

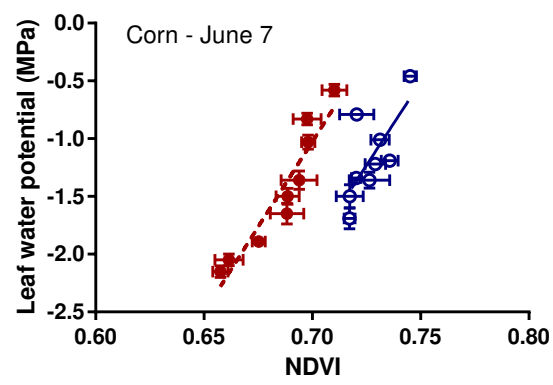

E

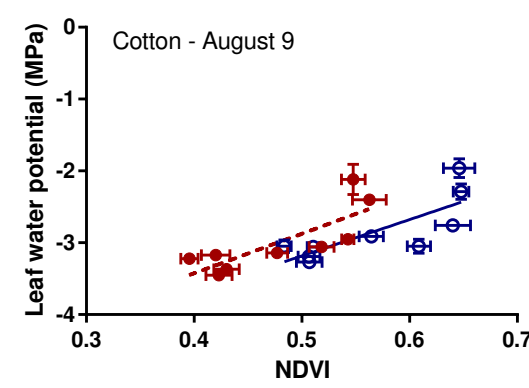

B

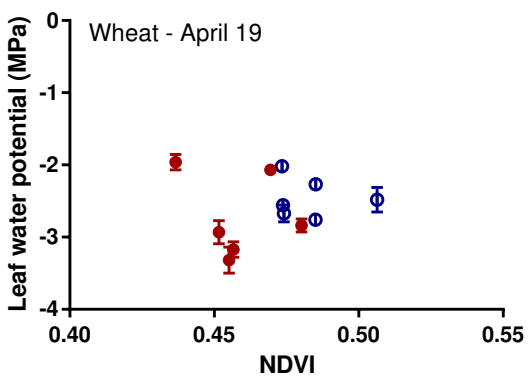

D

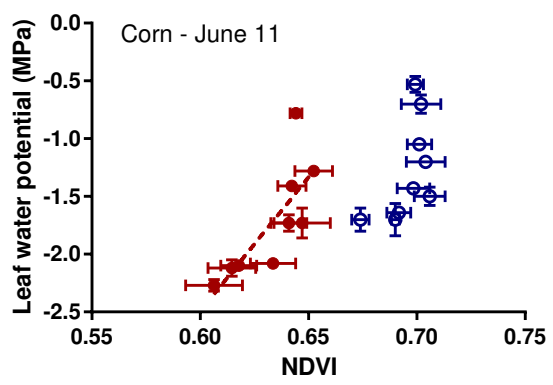

Deficit irrigation

๑ Full irrigation

Figure 7. Relationship between leaf water potential and NDVI for wheat (A, B), corn (C,D) and cotton (E) based on measured values made under different irrigation regimes. For wheat, the measurement was made on April 12 (135 DAP) and 19 (142 DAP), corn was on June 7 (93 DAP) and 11 (97 DAP), and cotton on August 9, 2019 (122 DAP). For a group of data in which the linear relationship was statistically significant, a best-fit line was drawn; otherwise, no line was displayed. Data values measured under full irrigation are shown as open circles, and those measured under deficit irrigation are shown as solid circles. Further information of the liner regressions is displayed in Table 2. 
Table 5. Percentage errors in $m$ and $c$ for the significant linear regressions using the ordinary least-squares (OLS) and weighted leas-squares (WLS) method.

\begin{tabular}{c|ccccc}
\hline Crop & Date & Irrigation $\dagger$ & $n$ & $\frac{\delta m}{m}(\%)$ OLS/WLS & $\frac{\delta c}{c}(\%)$ OLS/WLS \\
\hline Wheat & Apr. 12 & F & 8 & $12 / 10$ & $13 / 12$ \\
\hline Corn & Jun. 7 & D & 9 & $13 / 11$ & $12 / 10$ \\
& Jun. 7 & F & 9 & $36 / 18$ & $34 / 18$ \\
& Jun. 11 & D & 9 & $31 / 33$ & $28 / 32$ \\
\hline Cotton & Aug. 9 & D & 9 & $28 / 22$ & $13 / 10$ \\
& Aug. 9 & F & 9 & $30 / 27$ & $15 / 13$ \\
& Aug. 9 & D/F & 18 & $23 / 18$ & $10 / 8$ \\
\hline
\end{tabular}

the relationship between NDVI and LWP separately across the different crop and different irrigation treatments (Fig. 7). For wheat, there was an unclear or negative relationship between NDVI and LWP (Fig. 7A), while for corn and cotton, the relationship was positive. Though in the case of corn under full irrigation on June 11, 2018, the slope of the linear regression was not significantly different from zero (Fig. 7B,C). For those statistically significant regression lines shown in Fig. 7, further test indicated that, within corn or cotton, the slopes of the regressions lines are not significantly different, but the $y$-intercepts are significantly different (Table 2). Despite the low number of data points used in fitting the linear regression models, the relationships are generally strong as evidenced in the high $\mathrm{R}^{2}$ values in Table 2 .

\section{Uncertainty analysis of NDVI and leaf water potential}

Table 3 shows the uncertainties of the regression coefficients for the six significant linear regressions using the OLS method. In the last column of this table, the relative errors of the predicted LWP are shown. Since there was no statistical significance in regression coefficients between two cotton datasets (full vs. deficit irrigation), they were combined to form a larger dataset for further analysis. This is shown in the last row of Table 3 . We can see that the prediction errors were large, with the best being $34 \%$ when the two cotton datasets were combined. However, when the uncertainties in both coordinates were considered in the least-squares regression analysis using the WLS method, the uncertainties in both coefficients were reduced, and also reduced were the prediction errors (Table 4). Further calculation details of the results in Tables 3 and 4 are shown in Supplementary Dataset S3.

The difference between the results using two regression methods was further illustrated by the relative errors of the regression coefficients $m$ and $c$. As seen in Table 5, the WLS method yielded lower relative sizes of the uncertainties for the coefficients, as compared with the OLS method, except for corn measured on June 11. The latter case was likely due to the very high relative errors in measured NDVI for corn on this day, as shown in Table 6.

The 20 sets of resampled LWP values and the corresponding uncertainties for cases of 2 and 3 resampled values of LWP are shown in columns 1-40 of Supplementary Datasets S4 and S5, respectively. The resultant model coefficients and their uncertainties after these resampled LWP values were used as inputs to the OLS procedure of 'Isq.mac' are shown in columns 41-44 of Supplementary Datasets S4 and S5, respectively. The resultant model coefficients and their uncertainties using the WLS procedure of 'LLS(SIGMAS).xls' are shown in Supplementary Datasets S6 and S7, respectively. The results of statistical resampling indicate that reducing the sample size of LWP to 2 or 3 significantly increased the uncertainties of the estimated coefficients $m(0.92$ vs. 0.77$)$ and $c(0.48$ vs. 0.39$)$ as compared with the respective uncertainties when the original 4 replicates of LWP were used as inputs to the WLS method (Fig. 8). Reducing the sample size of LWP also increased the prediction uncertainty of LWP to 0.32 (from 0.27 using the WLS method as seen in Table 4). However, there was no significant difference in the uncertainty of either coefficient when the OLS method was used, as seen by the dashed lines passing through or touching the error bars of the resampled values using the OLS method (Fig. 8). This result was anticipated since no errors from the individual observations of NDVI or LWP were considered in the OLS method.

\section{DISCUSSION}

Five out of the six significant linear regressions relating NDVI to LWP yielded positive slopes (Fig. 7 and Table 2), suggesting that an increased value of NDVI was associated with a less negative value of 
Table 6. Measurement uncertainties $(\delta)$ relative to measurement ranges $(R)$ of NDVI and LWP (expressed as percentage) observed in different crops/days at Uvalde in 2018.

\begin{tabular}{c|ccccc}
\hline Crop & Date & Irrigation $\dagger$ & $n$ & $\frac{\delta_{N D V I}}{R_{N D V I}}(\%)$ & $\frac{\delta_{L W P}}{R_{L W P}(\%)}$ \\
\hline Wheat & Apr. 12 & $\mathrm{F}$ & 8 & - & 6.0 \\
\hline Corn & Jun. 7 & $\mathrm{D}$ & 9 & 10.5 & 3.8 \\
& Jun. 7 & $\mathrm{F}$ & 9 & 10.5 & 3.8 \\
& Jun. 11 & $\mathrm{D}$ & 9 & 19.8 & 3.7 \\
\hline Cotton & Aug. 9 & $\mathrm{D}$ & 9 & 6.6 & 5.3 \\
& Aug. 9 & $\mathrm{F}$ & 9 & 6.4 & 5.9 \\
\hline
\end{tabular}
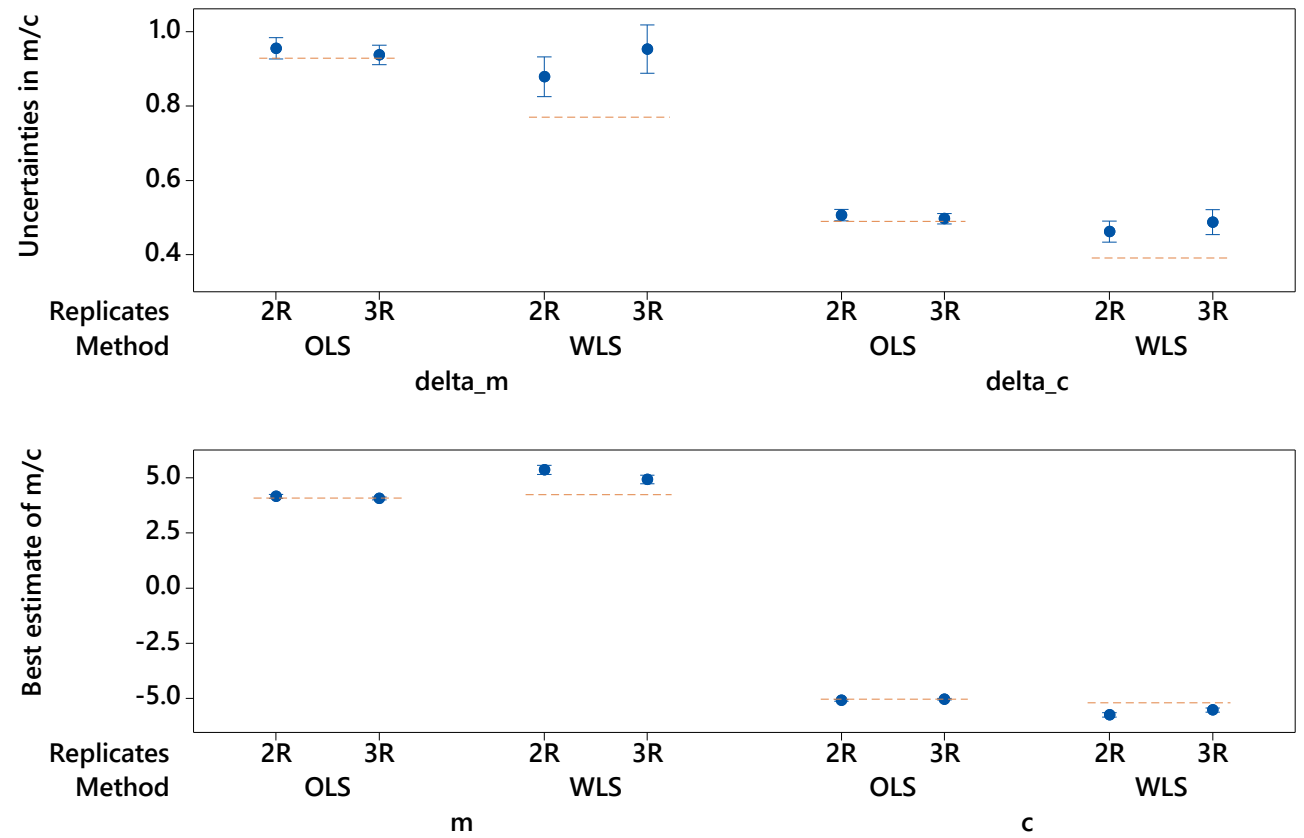

Figure 8. Best estimates of regression coefficients $m$ and $c$ and their uncertainties using 20 random resamples of 2 or 3 replicates of cotton LWP drawn from the original 4 replicates. Error bars indicate \pm 1 standard error of the means (SEM) and dotted lines show the values of the regression coefficients, or their uncertainties, when errors of LWP were based on all 4 replicates of LWP using the method of ordinary least-squares (OLS) or weighted least-squares (WLS). 
LWP. This trend was similar to that obtained in some other studies (Mastrorilli et al., 2010; Baluja et al., 2012; Maciel et al., 2020). In particular, the magnitudes of both the $y$-intercepts and slopes for cotton obtained in our study using the WLS method (see Table 4) were closely comparable with the respective values of an equation for coffee, $\mathrm{LWP}=-4.329+4.806 \mathrm{NDVI}\left(\mathrm{R}^{2}=0.82\right)$, obtained by Maciel et al. (2020). The negative slope found in the well-watered wheat on April 12, 2018, however, was rather perplexing. We also had three datasets in which no significant linear relation between LWP and NDVI was established (see Fig. 7A,B). Furthermore, the NDVI values in plots of deficit irrigation being higher than those of full irrigation on this same date (April 12) was also unexpected. The higher reflectance at the red band for wheat at full irrigation (Fig. 6A) suggests that wheat leaves under full irrigation were stressed more than those under deficit irrigation, a trend opposite of that of the typical stress responses of leaf reflectance in the VIS band (Carter, 1993), in which an increased red band reflectance was observed due to reduced absorption from the stress-related reduction in photosynthetic pigments. The observed lodging related to the Hessian fly infection in our wheat plots may have hastened the senescence during this early grain-filling stage, especially for the full irrigation plots. This can be inferred from Fig 4A, in which, toward end of the measurements, a faster reduction of LAI was observed in full irrigation plots than those in deficit irrigation. The above discussion casts doubt for the LWP-NDVI relation of wheat in Fig. 7 as being representative of the normal conditions.

Although all the six significant linear regressions in Table 2 showed high coefficients of determination, the uncertainties in both the estimated best model coefficients of $m$ and $c$ and in the predicted LWP were large (Tables 3 and 4), especially for corn and wheat. Importantly, taking into consideration the uncertainties of both LWP and NDVI led to reduced uncertainties for the model coefficients, as well as reduced upper bounds of the uncertainties in the predicted LWP using the average NDVI values (Tables 4 and 5, Supplementary Dataset S3). One exception was found in the case of corn measured on June 11, which was likely due to the very high relative error in measured NDVI for corn (Table 6). A notable finding is that the prediction uncertainty for the combined cotton samples was reduced from $34 \%$ to $27 \%$ after the WLS method was used. To what extent this effect (of reduced prediction uncertainty associated with the use of WLS) also applies to a different context of biological data analysis is not intuitively evident just by inspecting the relevant equations for calculating the uncertainties of the model coefficients, such as Eq. 9. But our experience of using this method in our data analysis suggests a promising outcome, with implications to other studies involving linear regressions of experimentally measured variables. The WLS method we used in this study was due to Reed (2010), but the solution of the problem was the result of multiple efforts dating back to the work of York (1966) and others, and later of Reed $(1989,1992)$.

With the maximum prediction error being $27 \%$ for combined cotton samples, the equation developed in this study may only be able to separate the differences in LWP between the extreme crop varieties growing under field conditions as seen in an example shown in Supplementary Fig. S4 (Dong and Mott, 2021) and also in Mart et al. (2016). To increase the range of variation of NDVI when variables such as green biomass or leaf area index are controlled in order to detect the variability of LWP, it may be necessary to create a wide range of water availability, possibly including both well-watered and stressed treatments. In addition, stronger signals due to changes in LWP may be captured by sensors with wider NIR bands, preferably reaching $1000 \mathrm{~nm}$ (Peñuelas and Filella, 1998; Elsayed et al., 2011), yet a wider band may incur more noise outside the biological signal targeted. Further studies are needed to confirm if the above strategies may help to reduce the relative errors as depicted in Table 6. In particular, additional research is needed to understand why under some circumstances, such as in cotton in our study, the range of NDVI measurement was wider and the uncertainty relative to the measurement range was smaller than in other situations, such as in corn.

Using statistical resampling, we showed that the beneficial effect of reduced model uncertainties due to the use of the WLS method diminished if the sample size of LWP is reduced (Fig. 8). In the case of combined cottons samples, reducing the sample size of LWP from 4 to 2 or 3 increased the prediction uncertainty of the model from $27 \%$ to to $32 \%$, a value closer to that obtained using the unweighted least-squares (34\% as seen in Table 3). This result emphasized the importance of maintaining or not reducing the sample size of LWP while calibrating the LWP-NDVI equations, even though the field measurement of LWP is time-consuming using some of the traditional methods (Cheung et al., 1975; Bennett et al., 1986).

Since ACS-430 is an active sensor that has its own light source, the impact of changes in solar angle at different times of a day was assumed to be small, although Kim et al. (2012) observed some 
changes in canopy reflectance within a day. In addition, we assumed that the effects of changes in diurnal leaf movement (Wang et al., 2004; Greenham et al., 2015; Cal et al., 2018), leaf area shrinkage (Hilty et al., 2009; Dong et al., 2011), as well as chlorophyll positioning (Maai et al., 2020), were minimum to our measured values of NDVI, and the key signals captured by our active spectral sensor, which was consistently positioned at a common height on the sensing frame looking down vertically at the plant canopy, originated mainly from the changes in leaf water status of the closed canopies of wheat, corn or cotton. We noted a moderate correlation between air temperature and NDVI for the combined corn/cotton samples $\left(\mathrm{R}^{2}=0.21\right.$; see Supplementary Fig. S5), which was in contrast to the strong correlation between LWP and NDVI in the combined data $\left(\mathrm{R}^{2}=0.78\right)$. Our field experience also indicated that the Crop Circle sensor needs more time (perhaps at least one hour) to warm up under a lower air temperature condition, such as that encountered in the early morning of April 12, 2018 when measuring wheat (Supplementary Fig. S2). Apparently, more rigorous approaches involving controlled experiments are needed to fully resolve the impact of these potential confounding effects, and those of other environmental factors mentioned above, on accurate sensing of LWP remotely using spectral reflectance from plant canopies.

In this study, our analysis was focused on the use of NDVI to indicate LWP of selected crop plants, although a number of other vegetation indices can also be derived from the same sensor as used here. Using the same active sensor, Dong et al. (2021) showed that, similar to NDVI, the red band reflectance and re-normalized difference vegetation index (RDVI) explained $>62 \%$ of the variation in shoot water content of sesame during drydown. Zarco-Tejada et al. (2012) found that RDVI was more strongly related to LWP than was NDVI in a citrus orchard $\left(R^{2}=0.44\right.$ vs. $\left.R^{2}=0.24\right)$. Ramoelo et al. (2015) demonstrated that normalized water index (NDWI) explained 70\% of LWP of selected plants in an indigenous vegetation in South Africa. These additional indices, as well as others, such as the normalized difference moisture index (NDMI) derived from Landsat (https://www.usgs.gov/core-science-systems/nli/landsat/normalizeddifference-moisture-index), may be useful for further in-depth studies on the relationship between spectral indices and plant water status.

Another limitation of our study originates from the fact that NDVI was measured at the canopy level while LWP was from the leaf level. The extent to which this mis-match and the associated uncertainty may have affected a reasonable characterization of the canopy water status was not assessed in this study, since it was difficult to conduct a comprehensive survey of LWP distribution within the studied plant canopies using the pressure chamber method. Although the vertical gradient of LWP within canopies of most agricultural plants should be modest, considering the theoretical and measured gradient of about $-0.01 \mathrm{MPa} \mathrm{m}^{-1}$ (Scholander et al., 1965; Bauerle et al., 1999), leaf water status can vary in relation to leaf age (Jordan et al., 1975) and position (Bader et al., 2014) within plant canopies. One way of workaround is to measure both NDVI and LWP at the leaf level (Stimson et al., 2005). However, a lot of times, the work of remote sensing of plant water status is motivated by the needs to characterize crop genotypes under field conditions, and thus the data from the limited measurements using the pressure chamber method is often used as a canopy surrogate to correlate with remotely measured canopy features using ground based sensors (such as in this current study) and sensors on board an unmanned aerial vehicle (Baluja et al., 2012; Zarco-Tejada et al., 2012) or satellite (Maciel et al., 2020). We are unaware of the availability of an experimental method that can readily be used to characterize the LWP profile of a full plant canopy. Yet there is hope to rely on continuously measured leaf turgor pressure from different positions of a plant canopy using a set of magnetic-based ZIM-probes (Bader et al., 2014; Bramley et al., 2015; Martínez-Gimeno et al., 2017). Notably, the fine resolution in the time scale of the ZIM-probes can complement the fine spatial resolution of the the aerial-based sensors, such as that used by Zarco-Tejada et al. (2012), to achieve an optimal calibration of leaf water status under field conditions.

\section{CONCLUSIONS}

Our study demonstrated that, NDVI, a well-known vegetation index frequently used to indicate vegetation biomass and LAI, can also be of value in estimating LWP of growing plants, if sufficient care is taken to minimize the confounding effects from other factors such as changes in LAI. In particular, we addressed a few important methodical issues regarding the uncertainties of the regression models relating NDVI to LWP, which have not been well-understood in current literature pertaining to both the ground-based, aerial and satellite remote sensing, to quantify LWP using NDVI. This was achieved through the use of a custom-built phenotyping cart, as well as the application of the OLS and WLS methods for statistical 
error analysis of the field data. Our data analyses helped provide a deeper understanding of the factors influencing the LWP-NDVI relationship using readily available, low-cost spectral sensors. Our results showed that obtaining a high value of coefficient of determination did not guarantee a high prediction precision in the regression model relating NDVI to LWP. To improve the precision of using NDVI to predict LWP, measurement uncertainties in both LWP and NDVI should be considered through the use of the WLS regression, and the sample size of LWP should not be reduced when using the traditional pressure chamber method. Our data also showed instances in which the LWP-NDVI relationship was not significant or even suspicious (such as in wheat); these need to be investigated further in future studies. Finally, the uncertainty relative to the measurement range of NDVI may need to be controlled or reduced. This may be achieved by using sensors with NIR bands that can capture stronger or more stable signals of leaf water variability, sampling uniform, closed canopies to prevent confounding effects of changes in LAI/green biomass and plant disease status from influencing the signals of NDVI, and targeting crop varieties growing under variable and stress conditions with their coincident LWP values. The methods used in this paper may be extended to future studies of remote sensing of LWP in which additional spectral indices will be evaluated and tested, and more high-throughput LWP measurement methods be developed to characterize the full canopies of field crops.

\section{ACKNOWLEDGMENTS}

We thank Sixto Silva at the Texas A\&M AgriLife Research and Extension Center at Uvalde for fabricating the frame structure of the push-wheel phenotyping cart and the back-pack sensing frame. We also appreciate Ray King for managing the field crops. We are grateful to the editor and three peer reviewers for insightful suggestions that helped to improve this paper. We thank Jennifer Dong for editing the main text. X.D. would like to dedicate this work to the memory of his M.S. and Ph.D. advisor, Prof. Xinshi Zhang (1934-2020).

\section{REFERENCES}

Aguilar, C., Zinnert, J. C., Polo, M. J., and Young, D. R. (2012). NDVI as an indicator for changes in water availability to woody vegetation. Ecological Indicator, 23:290-300.

Bader, M. K.-F., Ehrenberger, W., Bitter, R., Stevens, J., Miller, B. P., Chopard, J., Rüger, S., Hardy, G. E. S. J., Poot, P., Dixon, K. W., Zimmermann, U., and Veneklaas, E. (2014). Spatio-temporal water dynamics in mature Banksia menziesii trees during drought. Physiologia Plantarum, 152:301-315.

Bai, G., Ge, Y., Hussain, W., Baenziger, P. S., and Graef, G. (2016). A multi-sensor system for high throughput field phenotyping in soybean and wheat breeding. Computers and Electronics in Agriculture, 128:181-192.

Baluja, J., Diago, M. P., Balda, P., Zorer, R., Meggio, F., Morales, F., and Tardaguila, J. (2012). Assessment of vineyard water status variability by thermal and multispectral imagery using an unmanned aerial vehicle (UAV). Irrigation Science, 30:511-522.

Barker, III, J., Zhang, N., Sharon, J., Steeves, R., Wang, X., Wei, Y., and Poland, J. (2016). Development of a field-based high-throughput mobile phenotyping platform. Computers and Electronics in Agriculture, 122:74-85.

Bauerle, W. L., Hinckley, T. M., Cermak, J., Kucera, J., and Bible, K. (1999). The canopy water relations of old-growth douglas-fir trees. Trees: Structure and Function, 13:211-217.

Bennett, J. M., Cortes, P. M., and Lorens, G. F. (1986). Comparison of water potential components measured with a thermocouple psychrometer and a pressure chamber and the effects of starch hydrolysis. Agronomy Journal, 78:239-244.

Bevington, P. R. and Robinson, D. K. (2003). Data Reduction and Error Analysis for the Physical Sciences. McGraw-Hill, New York, NY USA, 3 edition.

Bramley, H., Bitter, R., Zimmermann, G., and Zimmermann, U. (2015). Simultaneous recording of diurnal changes in leaf turgor pressure and stem water status of bread wheat reveal variation in hydraulic mechanisms in response to drought. Functional Plant Biology, 42:1001-1009.

Bronson, K. F., White, J. W., Conley, M. M., Hunsaker, D. J., Thorp, K. R., French, A. N., Mackey, B. E., and Holland, K. H. (2017). Active optical sensors in irrigated durum wheat: Nitrogen and water effects. Agronomy Journal, 109:1-12.

Cal, A. J., Sanciangco, M., Rebolledo, M. C., Luquet, D., Torres, R. O., McNally, K. L., and Henry, A. 
(2018). Leaf morphology, rather than plant water status, underlies genetic variation of rice leaf rolling under drought. Plant, Cell and Environment, 42:1532-1544.

Cantrell, C. A. (2008). Technical Note: Review of methods for linear least-squares fitting of data and application to atmospheric chemistry problems. Atmospheric Chemistry and Physics, 8:5477-5487.

Carlson, T. N. and Ripley, D. A. (1997). On the relation between NDVI, fractional vegetation cover, and leaf area index. Remote Sensing of Environment, 62:241-252.

Carter, G. A. (1993). Responses of leaf spectral refletance to plant stress. American Journal of Botany, 80:239-243.

Cheung, Y. N. S., Tyree, M. T., and Dainty, J. (1975). Water relations parameters on single leaves obtained in a pressure bomb and some ecological interpretations. Canadian Journal of Botany, 53:1342-1346.

Deming, W. E. (1943). Statistical Adjustment of Data. Wiley, New York, NY, USA.

Dong, X., Feng, G., and Zemach, I. (2021). Using normalized difference vegetation index to estimate sesame drydown and seed yield. Journal of Crop Improvement, 35:508-521.

Dong, X. and Mott, D. A. (2021). Leaf osmotic potential and morphological traits of 43 cotton varieties growing in a rainfall gradient from southwest to central Texas. In Boyd, S., Huffman, M., Krogman, L., and Sarkissian, A., editors, Proceedings of the 2021 Beltwide Cotton Conferences, pages 193-197, Virtual. National Cotton Council of America.

Dong, X., Patton, B., Nyren, P., Limb, R., Cihacek, L., Kirby, D., and Deckard, E. (2011). Leaf-water relations of a native and an introduced grass species in the mixed-grass prairie under cattle grazing. Applied Ecology and Environmental Research, 9:311-331.

Elsayed, S., Mistele, B., and Schmidhalter, U. (2011). Can changes in leaf water potential be assessed spectrally? Functional Plant Biology, 38:523-533.

Gago, J., Douthe, C., Coopman, R. E., Gallego, P. P., Ribas-Carbo, M., Flexas, J., Escalona, J., and Medrano, H. (2015). UAVs challenge to assess water stress for sustainable agriculture. Agricultural Water Management, 153:9-19.

Gong, P., Pu, R., Biging, G. S., and Larrieu, M. R. (2003). Estimation of forest leaf area index using vegetation indices derived from hyperion hyperspectral data. IEEE Transactions on Geoscience and Remote Sensing, 41:1355-1362.

Grant, L. (1987). Diffuse and specular characteristics of leaf reflectance. Remote Sensing of Environment, 22:309-322.

Greenham, K., Lou, P., Remsen, S. E., Farid, H., and McClung, C. R. (2015). TRiP: Tracking rhythms in plants, an automated leaf movement analysis program for circadian period estimation. Plant Methods, $11: 33$.

Hilty, J., Pook, C., and Leuzinger, S. (2009). Water relations determine short time leaf growth patterns in the mangrove Avicennia marina (Forssk.) Vierh. Plant, Cell and Environment, 42:527-535.

Hunink, J. E., Contreras, S., Soto-García, M., Martin-Gorriz, B., Martinez-Álvarez, V., and Baille, A. (2015). Estimating groundwater use patterns of perennial and seasonal crops in a Mediterranean irrigation scheme, using remote sensing. Agricultural Water Management, 162:47-56.

Hunsaker, D. J., Fitzgerald, G. J., French, A. N., Clarke, T. R., Ottman, M. J., and Pinter, Jr., P. J. (2007). Wheat irrigation management using multispectral crop coefficients: II. Irrigation scheduling performance, grain yield, and water use efficiency. Transactions of the American Society of Agricultural and Biological Engineers, 50:2035-2050.

Ihuoma, S. O. and Madramootoo, C. A. (2017). Recent advances in crop water stress detection. Computers and Electronics in Agriculture, 141:267-275.

Irmak, A., Ratcliffe, I., Ranade, P., Hubbard, K. G., Singh, R. K., Kamble, B., and Kjaersgaard, J. (2011). Estimation of land surface evapotranspiration with a satellite remote sensing procedure. Great Plains Research, 21:73-88.

Jones, H. G. (2004). Irrigation scheduling: advantages and pitfalls of plant-based methods. Journal of Experimental Botany, 55:2427-2436.

Jones, H. G. and Vaughan, R. A. (2010). Remote Sensing of Vegetation: Principles, Techniques and Applications. Oxford University Press, New York, N. Y.

Jordan, W. R., Brown, K. W., and Thomas, J. C. (1975). Leaf age as a determinant in stomatal control of water loss from cotton during water stress. Plant Physiology, 56:595-599.

Kim, Y., Glenn, D. M., Park, J., Ngugi, H. K., and Lechman, B. L. (2012). Characteristics of active spectral sensor for plant sensing. Transactions of the American Society of Agricultural and Biological 
Engineers, 55:293-301.

Knapp, A. K. and Carter, G. A. (1998). Variability in leaf optical properties among 26 species from a broad range of habitats. American Journal of Botany, 85:940-946.

Kramer, P. J. (1988). Measurement of plant water status: Historical perspectives of and current concerns. Irrigation Science, 9:275-287.

Kumar, A. and Singh, D. P. (1998). Use of physiological indices as a screening technique for drought tolerance in oilseed Brassica species. Annals of Botany, 81:413-420.

Lybanon, M. (1984). A better least-squares method when both variables have uncertainties. American Journal of Physics, 52:22-26.

Maai, E., Nishimura, K., Takisawa, R., and Nakazaki, T. (2020). Diurnal changes in chloroplast positioning and photosynthetic traits of $\mathrm{C}_{4}$ grass finger millet. Plant Production Science, 23:477-489.

Maciel, D. A., Silva, V. A., Alves, H. M. R., Volpato, M. M. L., de Barbosa, J. P. R. A., de Souza, V. C. O., Santos, M. O., de Oliveira Silveira, H. R., Dantas, M. F., de Freitas, A. F., Carvalho, G. R., and dos Santos, J. O. (2020). Leaf water potential of coffee estimated by Landsat-8 images. PLOS ONE, 15(3): $\mathrm{e} 0230013$.

Mart, K. B., Veneklaas, E. J., and Bramley, H. (2016). Osmotic potential at full turgor: an easily measurable trait to help breeders select for drought tolerance in wheat. Plant Breeding, 135:279-285.

Martínez-Gimeno, M. A., Castiella, M., Rüger, S., Intrigliolo, D. S., and Ballester, C. (2017). Evaluating the usefulness of continuous leaf turgor pressure measurements for the assessment of Persimmon tree water status. Irrigation Science, 35:159-167.

Mastrorilli, M., Campi, P., Palumbo, A. D., and Modugno, F. (2010). Ground-based remote sensing for assessing tomato water-status. Italian Journal of Agronomy, 5:177-183.

McIntyre, G. A., Brooks, C., Compston, W., and Turek, A. (1966). The statistical assessment of Rb-Sr isochrons. Journal of Geophysical Research, 71:5459-5468.

Murray, S., Knox, L., Hartley, B., Mendez, M., Richardson, G., Thomasson, A., Shi, Y., Rajan, N., Neely, H., Bagavathiannan, M., Dong, X., and Rooney, W. (2016). High clearance phenotyping systems for season-long measurement of corn, sorghum and other row crops to complement unmanned aerial vehicle systems. In Proc. SPIE 9866, Autonomous Air and Ground Sensing Systems for Agricultural optimization and Phenotyping, page doi: 10.1117/12.2228323.

Peñuelas, J. and Filella, I. (1998). Visible and near-infrared reflectance techniques for diagnosing plant physiological status. Trends in Plant Science, 3:151-156.

Press, W. H., Teukolsky, S. A., Vetterling, W. T., and Flannery, B. P. (1992). Numerical Recipes in FORTRAN: The Art of Scientific Computing. Cambridge University Press, New York, N.Y., USA, 2 edition.

Pu, R., Ge, S., Kelly, N. M., and Gong, P. (2004). Spectral absorption features as indicators of water status in coast live oak (Quercus agrifolia) leaves. International Journal of Remote Sensing, 24:1799-1810.

Rallo, G., Minacapilli, M., Ciraolo, G., and Provenzano, G. (2014). Detecting crop water status in mature olive groves using vegetation spectral measurements. Biosystems Engineering, 128:52-68.

Ramoelo, A., Dzikiti, S., van Deventer, H., Maherry, A., Cho, M. A., and Gush, M. (2015). Potential to monitor plant stress using remote sensing tools. Journal of Arid Environments, 113:134-144.

Reed, B. C. (1989). Linear least-squares fits with errors in both coordinates. American Journal of Physics, 57:642-646.

Reed, B. C. (1992). Linear least-squares fits with errors in both coordinates. II: Comments on parameter variances. American Journal of Physics, 60:69-62.

Reed, B. C. (2010). A spreadsheet for linear least-squares fitting with errors in both coordinates. Physics Education, 45:93-96.

Reed, B. C. (2015). Straight-line fits with uncertainties in both coordinates: from Gauss to spreadsheets. Physica Scripta, 90:128001.

Rouse, J. W., Haas, R. H., Schell, J. A., and Deering, D. W. (1974). Monitoring vegetation systems in the great plains with ERTS. In Fraden, S., Marcanti, E. P., and Becker, M. A., editors, Third ERTS-1 Symposium., NASA SP-351, pages 309-317, Washington D. C. NASA.

Scholander, P. F., Hammel, H. T., Bradstreet, E. D., and Hemmingsen, E. A. (1965). Sap pressure in vascular plants. Science, 148:339-346.

Slaton, M. R., Hunt, Jr., E. R., and Smith, W. K. (2001). Estimating near-infrared leaf reflectance from leaf structural characteristics. American Journal of Botany, 88:278-284. 
Stimson, H. C., Breshears, D. D., Ustin, S. L., and Kefauver, S. C. (2005). Spectral sensing of foliar water conditions in two co-occurring conifer species: Pinus edulis and Juniperus monosperma. Remote Sensing of Environment, 96:108-118.

Syvertsen, J. P. and Levy, Y. (1982). Diurnal changes in citrus leaf thickness, leaf water potential and leaf to air temperature difference. Journal of Experimental Botany, 33:783-789.

Taylor, J. R. (1982). An Introduction to Error Analysis. A Series of Books in Physics. University Science Books, Mill Valley, CA.

Wang, C., Isoda, A., Li, Z., and Wang, P. (2004). Transpiration and leaf movement of cotton cultivars grown in the field under arid conditions. Plant Production Science, 7:266-270.

White, J. W. and Conley, M. M. (2013). A flexible, low-cost cart for proximal sensing. Crop Science, 53:1646-1649.

Williamson, J. H. (1968). Least-squares fitting of a straight line. Canadian Journal of Physics, 46:18451847.

York, D. (1966). Least-squares fitting of a straight line. Canadian Journal of Physics, 44:1079-1086.

York, D. (1969). Least squares fitting of a straight line with correlated errors. Earth and Planetary Science Letters, 5:320-324.

York, D., Evensen, N. M., Martínez, M. L., and Delgado, J. D. B. (2004). Unified equations for the slope, intercept, and standard errors of the best straight line. American Journal of Physics, 72:367-375.

Zarco-Tejada, P. J., González-Dugo, V., and Berni, J. A. J. (2012). Fluorescence, temperature and narrowband indices acquired from a UAV platform for water stress detection using a micro-hyperspectral imager and a thermal camera. Remote Sensing of Environment, 117:322-337.

Zhang, J., Liu, X., Liang, Y., Cao, Q., Tian, Y., Zhu, Y., Cao, W., and Liu, X. (2019). Using a portable active sensor to monitor growth parameters and predict grain yield of winter wheat. Sensors, 19:1108. 